\title{
KLARA ILE GÜNEŞ: DIJITALLEŞEN BIR ÇAĞDA INSSAN OLMAK
}

\author{
Klara and the Sun: Being Human in a Digitalised Era
}

\section{Ercan GÜROVA*}

\section{öz}

Kazuo Ishiguro'nun son romanı Klara ile Güneş (2021) çevresini ve insanları gözlemleyerek öğrenen bir insansı robotun merkezde olduğu bir insan-robot etkileşimi hikâyesi sunmaktadır. Klara adlı yapay arkadaş (YA) anlatıcının açısından sunulan olay örgüsü yalnızlık, özveri, umut ve sevginin anlamı gibi temaları ön plana çıkararak gittikçe dijitalleşen bir dünyada insan olmanın anlamı ve yeri doldurulabilir olup olmaması konusunu sorunsallaştırmaktadır. Bu çalışma gen modifikasyonu, otomasyonun yükselişi ve yol açtığı işsizlik, çevre sorunları gibi insanlığı tehdit eden yakıcı meseleler arasında bundan insan bireyinin nasıl etkileneceğini Ishiguro'nun romanını temel alarak Jürgen Habermas'ın görüşleri ışığında değerlendirmekte, yazarın insan-robot etkileşimi ve gelişimine dair bakış açısını robot etiği ile bağlantılı olarak açıklamaktadır. Yazar, insan-robot etkileşiminin üst düzeyde olduğu romanda materyalist bir bakış açısını olumsuzlayarak tinselci ve moralist bir anlatı kurgulamaktadır. İnsanın özünün ne olduğuna dair soruşturmaya yazarın verdiği cevap mekanik ve yapay bir dünyanın ötesinde insanın sınırsız duygu evreninde yatmaktadır ve insanı insan kılan değerleri görmek maddi bir bakış açısından sıyrılmakla mümkündür.

Anahtar Sözcükler: Ishiguro, Klara ile Güneş, insan, Habermas, bilim kurgu.

\section{ABSTRACT}

Kazuo Ishiguro's latest novel, Klara and the Sun (2021) presents a human-robot interaction story centered around a humanoid robot that learns by observing its environment and people. The plot presented from the point of view of Klara, the artificial friend $(\mathrm{AF})$, problematizes the meaning of being human and whether it is replaceable in an increasingly digital world by highlighting themes such as loneliness, self-sacrifice, hope and the meaning of love. This study evaluates how the human individual will be affected by the poignant issues that threaten humanity, such as gene modification, the rise of automation and the unemployment it causes, based on Ishiguro's novel and in the light of Jürgen Habermas's views. It also focuses on human-robot interaction and development in relation with robot ethics. The au-

\footnotetext{
* Dr. Öğr. Gör., Ankara Üniversitesi, Yabancı Diller Yüksekokulu, Ankara/Türkiye. E-posta: ercangurova@hotmail.com. ORCID: 0000-0001-5446-9013.
} 
thor constructs a spiritualist and moralist narrative in the novel where human-robot interaction is at a high level by negating the materialist perspective. The author's answer to the inquiry about what the essence of human is, lies in the infinite world of human emotions beyond a mechanical and artificial world and it is only possible to see human values by moving away from a materialist point of view.

Keywords: Ishiguro, Klara and the Sun, human, Habermas, science fiction.

\section{Giriş}

E. M. Forster'ın (1879-1970) "Makine Duruyor" [The Machine Stops] başlıklı bilim kurgu hikâyesini 1909'da yayınlamasından günümüze kadar insan-makine etkileşimi çeşitli dönüşümler geçirdi. İnsanlığa hizmet eden aygıtlardan dünyayı ve insan varoluşunu tehdit eden akıllı makinelere kadar farklı izleklerde yol alarak çeşitli anlatılar ortaya kondu. 1920'de ilk defa Josef ve Karel Capek Çekçe "angarya" ve "kulluk" anlamlarına gelen "robota" kelimesinden "robot" kelimesini türetip kullandılar (Wallach \& Allen, 2009: 62). Kelimenin kökeninden de anlaşıldığı üzere robot kavramı insana hizmet etme, onun işini kolaylaştırma ve ihtiyaçlarını giderme nesnesi olarak tasavvur edildi. Kendisine verilen komutu yerine getiren basit bir makine olmaktan karar alma yetisine sahip bir "eyleyici" (agent) olma konumuna geçtiğinde insana zarar gelmemesi için bir takım düzenlemeler yapmak gerekti. Isaac Asimov'un (1920-1992) üç robot kanunu insan varoluşunu önceleyen tavrıyla bu bağlamda son derece yaygınlaşacak ve yerleşik hale gelecek kurallar geliştirdi: "1. Robotlar, insanlara zarar veremez ya da eylemsiz kalarak onlara zarar gelmesine göz yumamaz. 2. Robotlar, Birinci Kanun'la çakışmadığı sürece insanlar tarafından verilen emirlere itaat etmek zorundadır. 3. Robotlar, Birinci ya da İkinci Kanun'la çakışmadığı sürece kendi varlıklarını korumak zorundadır" (Asimov, 2016: 7). Robotların git gide insansılaşıp “android” oldukları bir sonraki evrede androidler elektrikli koyunlar düşlemeye başladı (Philip K. Dick'in 1968'te yayınlanan aynı isimli romanı Androidler Elektrikli Koyun Düşler Mi?). Bilim kurgu yazınında gelişen robotlar zamanla uzaya çıktı, organik beden parçalarıyla entegre olup cyborg'lar haline de geldi. İnsana hizmet eden akıllı makine kimi zaman kıyametin habercisi sayıldı.

Baş döndürücü bir hızla gelişen akıllı teknolojiler ve dijital otomasyon çağında insan-robot etkileşimini ve muhtemel sonuçlarını ele alan romanlar daha çok görünürlük kazanmaya başladı. Çağdaş İngiliz Edebiyatının önde gelen isimlerinden Jeanette Winterson'ın yapay zeka, hibritlik ve insanötesilik konularını Mary Shelley'in Frankenstein (1818) eserine gönderme- 
lerle yazdığı Frankissstein (2019) romanı; lan Mcewan'ın alternatif bir tarih kurgusuyla yola çıktığı ve insansı robot Âdem'in sahibi ve kız arkadaşıyla yaşadığı gerilimli ilişkiyi ele alan Benim Gibi Makineler (2019) romanı; ve bu diziye eklenen son halka Nobel ödüllü yazar Kazuo Ishiguro'nun sekizinci romanı Klara ile Güneş (2021) bu görünürlüğün en önemli parçalarını oluşturmaktadır.

Bu çalışma genetik gelişmelerin ve biyoteknolojik atılımların insanı kuşattığı bir evrende insan doğasının bundan ne derecede etkileneceğini ve insan-robot etkileşiminde insanı insan kılan değerlerin neler olduğunu Ishiguro'nun son romanı üzerinden sorgulamaktadır. Günümüzde gen modifikasyonu ve robotik ilerleme insan doğasının geleceğine dair yeni tartışmaları da beraberinde getirmektedir. Alman felsefeci, sosyolog ve siyaset bilimcisi Jürgen Habermas (1929) genetik müdahale ve insan tasarımı tartışmalarında felsefi ve etik sorunları ele alarak insan doğasının araçsallaştırılmasının ne tür sakıncalara yol açabileceğini ve biyoteknolojik tasarım sonucu meydana gelecek bireylerin yaşam modellerinin olumsuz yanlarını insan Doğasının Geleceği adlı yapıtında ortaya koymaktadır. Habermas'a göre verili doğa ile yapay olarak yarattığımız doğa arasındaki çizgi bulanıklaşmakta, insan türünün kendi biyolojik evrimini kendi eline alması, diğer bir deyişle kendini optimize etme süreci hızlanmakta ve bu durum muhtemel gen manipülasyonlarına kapı aralamaktadır. Bu durumun yarattığı ciddi felsefi ve etik sorunların tartışıması gerekmektedir (Habermas, 2019: 3047). Ishiguro'nun insan-robot etkileşimini ele aldığı romanında insan doğasının geleceği ile ilgili taşıdığı kaygı ve çekincelerin Habermas'ın güncel eleştirileri ışığında daha anlaşılır ve kapsamlı bir şekilde değerlendirilebileceği düşünüldüğü için bu çalışmada düşünürün görüşleri temel alınmıştır.

\section{Insan Olmanın Anlamını Yeniden Düşünmek}

Japonya doğumlu İngiliz yazar Kazuo Ishiguro bilim kurgu alanında ilk eserini 2005'te yayınladığı Beni Asla Bırakma [Never Let Me Go] ile verdi. Başkalarına organlarını bağışlamak için yetiştirilen klonların hikâyesini anlatan bu distopik romanı daha sonra "kötümser değil ama üzücü bir kitap" olarak yorumlayan yazar bu bakış açısına daha ümitvar bir doku katmak için devam niteliğinde olmasa da başka bir karşılık bulma arayışının sonucu olarak Klara ile Güneş’i yazdı (URL-1).

iki romanın da yakın gelecekte geçmesi, bir ahlaki değişim barındırması, içindeki ileri teknoloji kavramının insanın ne olduğunu sorgulatması gibi ortak temalar iki anlatının bir tür yoldaşlığına işaret etmektedir. Bütün bu 
benzerliklere rağmen Klara ile Güneş yalnızlık, özveri, umut ve sevginin anlamı gibi konuları önceleyerek yaşadığımız veya yakın gelecekte yaşama olasılığı yüksek olan yaygın bir dijital dünyada insan olmanın ne anlama geldiğini, bir özü olup olmadığını ve insanın tamamen yeri doldurulabilir bir varlık olup olmadığı düşüncesini ele alarak sorunsallaştırmaktadır.

Klara ile Güneş, Amerika'da adı verilmeyen bir yerde, yakın bir gelecekte geçmektedir. Anlatıcısının Klara isimli bir çocuk robot olduğu ve diğer çocuk robotlar gibi kendilerine "yapay arkadaş" (YA) denilen bir mağazadan satın alınabilen bu gelişmiş yapay canlı, Josie isimli gizemli bir rahatsızlığı olan 14 yaşındaki kız çocuğuna arkadaşlık etmesi için satın alınır. Klara'nın görevi hem Josie'nin yalnızlığını gidermek hem de ona hizmet etmektir. Ishiguro'nun betimlediği bu dünyada otomasyonun yol açtığı işsizlik, gökyüzünü karartan kirlilik ve çevre sorunları, üst gelir sahibi ailelerin çocuklarına yaptırdığı uzaktan eğitim ve bunun getirdiği yalnızlık ve kaygının artışı gözlemlenmektedir.

Güneş enerjisiyle çalışan Klara, James H. Moor'un makineleri sınıflandırdığı "belirgin etik fail" [explicit ethical agent] kategorisine girmektedir (Moor, 2011: 16-17). Klara belli bir öz-farkındalığa, özgür iradeye ve amaçlılığa sahiptir. Her ne kadar kendisi tarafından satın alınan çocuğa göz kulak olmak ve ihtiyaçlarını karşılamak için programlanmış olsa bile kendi başına karar alabilmekte, gözlem yapıp anlam üretebilmekte ve özveri olarak sayılabilecek davranış kalıpları sergilemektedir.

Klara'nın gözlem yapıp öğrendiği konulardan biri duygusal karşıtlıklardır. Örneğin, Klara bir gün sokakta karşılaşıp mutluluktan birbirine sarılan bir çifti gördüğünde bu çiftin aynı zamanda neden ağladığını anlayacak; mutluluk ve acının aynı ayda hissedilebildiğini öğrenecektir. Benzer şekilde kavga eden taksicileri, bir gün yerde hareketsiz yatan bir evsizle köpeğinin ölmeyip ertesi gün hareket ettiğini gözlemleyecektir. Kendisini satın alacağını sandığı kişi tarafından hayal kırıklığına uğratıldığında mağaza yöneticisinin "Çocuklar hiç durmadan söz verirler... onu beklemiş olan zavallı YA'yı görmezden gelir, onun yerine başkasını seçer" diyerek tutulmayan vaatlerden bahsetmesi de Klara'nın öğrenmek zorunda kaldığı bir başka karşıtıktır (Ishiguro, 2021: 35).

Klara B2 model bir robot olarak tanıtılır. Her ne kadar kendisinden sonra geliştirilen B3 modeli kadar gelişkin olmasa da çocuklarla en başarılı uyumu yakalamış tür olarak tarif edilir. Bu başarılı uyumda Borenstein ve Pearson'un söz ettikleri "insansılık" [human-likenes], bir diğer deyişle robotun 
insan özelliklerini birebir yansıtıyor olması önemli bir rol oynamakta ve daha kolay duygusal bağ kurmayı sağlamaktadır (2012: 253). Diğer özellikleri ise mağaza yöneticisi tarafından şu şekilde özetlenir: "Etrafında gördüğü her şeyi özümleme ve harmanlama yeteneği... bunun sonucu olarak, şu anda, B3'ler de dahil olmak üzere, mağazadaki tüm YA'lardan daha incelikli bir anlayışa sahiptir" (Ishiguro, 2021: 43).

Bir "belirgin etik fail" olarak Klara "bakımın etik unsurları"ndan [ethical elements of care] dördünü de sergilemektedir: dikkat, yeterlilik, heveslilik, ve sorumluluk (Meacham \& Studley, 2017: 99). Josie'yi vaktinde uyandırmak, ders çalışmasına yardımcı olmak, rahatsızlığı ile ilgili sıra dışı bir uyarı aldığında annesine haber vermek, onun mutluluğu için erkek arkadaşı ve annesi ile iş birliği yapmak, sır saklamak, plan yapmak, söz vermek bu unsurlara verilebilecek örneklerden bazılarıdır.

Sahibine arkadaşlık ve hizmet etmek için gerçekleştirdiği bu görevleri yerinde getirirken Klara çeşitli duygularını açığa vurmakta, bunun yanı sıra gözlemleri sonucunda yeni duygular da geliştirmektedir. Örneğin, ailecek yakınlarda bir şelaleye piknik yapmak için gitme planına Josie son anda çıkan rahatsızlığı yüzünden dâhil olamadığında Klara hüzünlenmekte; ilk defa bir boğa ile karşılaştığında telaşa kapılıp korkmakta; Josie ve Rick'in keyifle oyun oynamasını gözlemlerken mutlu olmakta; insanlığın yalnızlığı seçme dürtüsü karşısında şaşkınlık duymakta; Josie'yi iyileştirecek bir yöntem bulma konusunda ise umutlu olabilmektedir. Klara bütün bu yönleriyle ShawGarlock'un tarif ettiği sadece bir işe yarayan araç [utilitarian] olmanın ötesinde duygusal [affective] bir robot olma özellikleri sergilemektedir (2009: 250).

Anlatının geçtiği yakın gelecekteki toplumsal uygulamalar her ne kadar ön planda gözükmese de olay örgüsünü anlamlı kılmakta ve distopik ayrıntılar barındırmaktadır. Çocukların birbirlerini evlerinde dönüşümlü toplandıkları "etkileşim toplantıları" yapılmakta, uzaktan eğitimle sürdürülen eğitim-öğretim yaşamını "yükseltilmiş çocuklar" denen bir tür "genetik artırma" yolu belirleyici kılmaktadır. Romanda bahsi geçen "genetik artırma" yöntemi Habermas'ın "insanın kendi varoluşunun biyolojik temelleriyle ilgili girişmekte olduğu kendini optimize etme" süreci ile yakından ilgilidir ( $\mathrm{Ha}$ bermas, 2019: 43). Nitekim genetik artırma yöntemiyle çocukların yaşamlarında ve kariyerlerinde başarılı olma şansları yükselmektedir. Belli toplulukları ıslah etme ve geri kalanlarından ayıklama şeklinde de tanımlanabilecek bir "öjenik" uygulamayı çağrıştıran genetik artırma yöntemi ile bir üst sınıf 
oluşturulmakta ve bunun etkisiyle ergenlik, gençlik yılları, üniversiteye kabul edilmeleri ve nihayetinde istihdam edilmeleri değişime uğramaktadır.

"Yükseltme" [lifting] olarak tarif edilen genetik artırmanın avantajları olduğu kadar riskleri de mevcuttur ve Josie'nin roman boyunca açıklanmayan gizemli rahatsızlığı bundan kaynaklanmaktadır. "Yetişen ile yapılan arasındaki ayrımın biyoteknoloji" aracılığıyla ortadan kaldırılması, diğer bir deyişle kalıtsal donanıma yönelik dışsal bir müdahalenin öngörülemez ve daimi sonuçları olabileceğini ve bunun "kişinin kendi yaşamını özerk olarak biçimlendirme özgürlüğünü sınırlandıracağını” Josie örneğinde takip etmek mümkündür. Çocukların kariyerleri, iş hayatları ve genel olarak gelecekleri adına ebeveynleri tarafından alınan genetik artırma kararı Habermas'ın dile getirdiği "kendimiz olarak var olduğumuz doğamız ile kendimize verdiğimiz organik donanım" arasındaki mesafeyi açmakta ve bulanıklaştırmaktadır (2019: 46-47).

Bir "yükseltilmiş çocuk" olamayıp o dünyanın ayrıcalıklarına erişemeyenleri ne mevcut şartlarda parlak bir gelecek beklemekte ne de gelecek nesiller adına karar verme mekanizmalarında söz sahibi olma olanakları mümkün olabilmektedir. Habermas'ın "şimdikilerin gelecektekiler üzerindeki iktidarı" diye tarif ettiği biyoteknoloji ve gen mühendisliği üzerinden yapılan uygulamaları bir iktidar aracı olarak kullananlar ve geleceği şekillendirenler hem günümüzün hem de yarınların muktedirleri olarak yön tayin edici ve modern dünyanın efendileri konumunu elde edeceklerdir (2019: 88). Romanda "yükseltilmiş bir çocuk" olmayan Josie'nin erkek arkadaşı Rick bu ayrıcalıklı dünyanın bir parçası olabilmek için bazı eğitim kurumlarının "yükseltilmemişler" için ayırdığı yüzde 2'den daha az kontenjanlarda yer edinmeye çalışmaktadır. Rick'in annesinin şu anda böyle bir kurumun yönetim kurulunda olan eski sevgilisi ile yıllar sonra bir araya gelip ondan aracı olmasını istemesi, Rick'in projeleri ve hayalleri ile çaresizce onu etkilemeye çalışması "yükseltilmiş çocukların" üst sınıfına dâhil olmayı ebeveynlerin ne derece ciddiye aldığını göstermekte ve çocuklar arasındaki ilişkileri de etkilemektedir:

Rick hiçbir zaman yükseltilmediyse de onun için hala düzgün bir seçenek var. Atlas Brookings az sayıda yükseltilmemiş öğrenci kabul ediyor. Hala bunu yapan tek doğru dürüst üniversite bu kaldı. ilke olarak buna inanıyorlar, şükürler olsun. Her yıl yalnızca birkaç çocuk alıyorlar, onun için, doğal olarak vahşi bir rekabet var. Ama Rick zekidir, kendini verirse ve belki biraz da uzman desteği... şansı var(Ishiguro, 2021: 129). 
Habermas ebeveynlerin çocukları üzerinde geri dönülemez ve daimi etkileri olabilecek karar almasını etik açıdan sorunlu bulmaktadır. Hırs ve deneycilik güdüleriyle hareket eden, gelecekte çocukla ilgili beklentileri bugünden tasarlayıp şekillendiren ebeveynlerin evlatlarına olan tavırlarını bir tür "şeyleşme" olarak görmektedir: "Ebeveyn, her hangi bir rıza almadan ve sadece kendi önceliklerine göre, adeta bir eşya söz konusuymuş gibi karar vermektedir" (2019: 92). "Şeyleşme" kavramı ile kastedilen bir sürecin veya ilişkinin nesne haline getirilmesi ve beraberinde bir yabancılaşmaya neden olmasıdır (Bewes, 2008: 23-24). Ebeveynin iyi niyetle hareket ettiğini iddia edip çocuğunun yaşamı ile ilgili ölümcül veya çok büyük hasarlar yaratabilecek düzeyde kritik kararlar alması, bu kararların varoluşsal sonuçlarının olabilmesi ebeveyn-çocuk arasındaki ilişkinin doğasına dair bir yabancılaşmayı da beraberinde getirmektedir. Josie'nin annesinin kendi kızı hakkında aldığı karar bunun çok tipik bir örneğidir: "Onun için her şeyin en iyisinin istedim. Anlıyor musun Klara? Onay verdim ve şimdi Josie hastalandı. Benim verdiğim karar yüzünden" (Ishiguro, 2021: 183).

Josie'nin adı verilmeyen gizemli rahatsızlığının yanı sıra roman ilerledikçe ablası Sal'in ölmüş olduğunu öğreniriz ancak bu konuda da aydınlatıcı bir bilgi verilmez. Onun da "yükseltme" konusunda verilen bir kurban olma ihtimali akla gelir. Sal'in kaybının yol açtığı keder Josie'nin zaman zaman ağırlaşan rahatsızlığı ile birleşince Josie'nin annesinin (Chrissie) çözümü bir kopya/taklit Josie'de aradığı ortaya çıkar. Bir gün atölyesine gittikleri Mr. Capaldi isimli ressamla tanıştırılan Klara Josie'nin üç boyutlu yapılmış maketiyle karşılaşır. Daha önce Sal için denenen ama başarısız olan yöntem bu sefer Josie için planlanmıştır: "Klara, biz senden yeni Josie'yi eğitmeni istemiyoruz. Biz senden o olmanı istiyoruz. Yukarda gördüğün o Josie, fark etmiş olduğun gibi boş. Eğer gün gelir de - umarım gelmez ama gelirse - öğrendiğin her şeyle beraber yukarda gördüğün Josie'nin içinde yaşamanı istiyoruz" (Ishiguro, 2021: 180).

Üstün gözlem ve öğrenme yeteneğine sahip Klara'nın Chrissie tarafından kızının hareketlerini ve muhtemel düşüncelerini doğaçlama olarak sergilemesini istemesi artık daha çok anlam kazanmaktadır. Gördüğü sonuçlardan memnun kalan Chrissie olası ikinci bir kaybın acısını hafifletmek istercesine Klara'dan ilerde kızını taklit etmesini istemektedir. Bu istek Habermas'ın "kendi olabilmek için kişinin, kendi vücudu içinde kendini evinde gibi hissetmesi gerekir; vücut kişisel varoluşun bedenleşmiş aracıdır" sözünü hatırlatmakta, kişinin varoluşunun fiziki görünüş ve karakter özelliklerinin birebir kopyalanması ile çözülebileceğini ima etmektedir (2019: 101). 
Klara'nın rolünü oynayacağı ikinci Josie'nin ne kadar gerçek Josie olup olmayacağına dair Chrissie'nin kaygılarını Mr. Capaldi yatıştırmaya çalışır. Insanın özüne dair materyalist bir bakışı yansıtan sözleriyle Capaldi insanın benzersizliğini, içimizde ulaşılamayacak bir cevher olma fikrini sert bir şekilde reddeder. Modern tıp ve teknolojinin insan biyolojisine dair argümanlarına başvurur. Josie'nin kopyalanması ile kaybedilecek hiçbir şey olmayacağını çünkü insanın fiziksel görünüşü ve karakter özellikleri ile bire bir taklit edilebileceğini ateşli bir şekilde savunur: "Orada bir şey yok. Josie'nin içinde, bu dünyanın Klara'larının devam ettiremeyeceği hiçbir şey yok. İkinci Josie bir kopya olmayacak. Tam anlamılla aynı olacak ve şu anda Josie'yi nasıl seviyorsan, onu da aynı şekilde sevmeye her türlü hakkın olacak. Senin ihtiyacın olan şey inanç değil. Sadece mantık" (Ishiguro, 2021: 181).

Capaldi'nin her türlü metafiziksel yaklaşımı bertaraf eden maddeci bakış açısında herhangi bir öze ihtiyaç yoktur ve insan varlığı kopyalanabilir bir maddeden başka bir şey değildir. îhtiyacımız olan şey "sadece mantık" vurgusunda "insan nedir" sorusuna verilen bir çeşit yanıt gizli gibidir: logos. Diğer bir deyişle, akıllı bir canlıdır. Maddi olmayan (mana) gibi varsaydığımız özellikler (sevgi, bilinç, şefkat vb.) aslında maddenin görüngülerinden başka bir şey değildir. Diyalektik materyalizme kapı aralayan bu bakış açısına göre her türlü mana ve rasyonalite de "doğadaki maddi evrimin ilerleyici bir sonucu" olmaktan ibarettir (Tura, 2011: 31).

Capaldi ve Chrissie'nin Klara'yı yeni Josie olması için ikna etmesi çok zor olmaz. Sahibine hizmet etmeye, onun mutluluğu için ne gerekiyorsa yapmaya programlanmış bir robot için bu teklif yeni bir görev addedilebilir: "Şu ana kadar görevim Josie'yi kurtarmaktı, onu iyileştirmekti, böyle düşünüyordum. Ama belki de bu daha iyi bir yoldur" (Ishiguro, 2021: 184). Klara'nın hünerli bir robot olarak Josie'nin yerini alabileceğine dair en büyük kaygıyı babası Mr. Paul dile getirir. Insan nedir sorusuna "beden, karakter ve zihin" yanıtını veren Mr. Capaldi'nin aksine Josie'nin babası için insan bunlardan öte bir anlam taşımakta ve kopyalanamayan bir öz barındırmaktadır. Bu öz mecazi anlamda kalbinin derinliklerinde olan bir şeydir:

Insan kalbine inanır mısın? Sadece organ anlamında sormuyorum besbelli ki. Şiirsel anlamda konuşuyorum. İnsan kalbi. Böyle bir şey olduğunu düşünüyor musun? Her birimizi özel yapan, birey yapan bir şey? Ve böyle bir şey olduğunu varsayarsak, o zaman Josie'yi hakikaten öğrenmen için yalnız onun tavırlarını değil, içinin derinliklerinde ne olduğunu da öğrenmen gerektiğini düşünmüyor musun? (Ishiguro, 2021: 188). 
Mr. Paul bu sözleriyle şüphesiz kalbin derinliklerindeki sevgiyi veya daha genel anlamda duygu dünyasını kastetmektedir. Çalışma yaşamlarımız da dâhil olmak üzere hayatın hemen her alanında yerimize geçebilecek olan robotlar duygusal yaşamlarımızda da yerimize geçebilir mi? İnsanın sadece fiziksel görünümünün ve karakter özelliklerinin bire bir kopyalanması onun yerinin rahatlıkla doldurulabileceğinin işareti olabilir? Mr. Paul'un kaygııları bu sorulara muhtemelen olumsuz cevap vereceğini göstermekte ve insan nedir, sorusuna Mr. Capaldi'nin verdiği diyalektik materyalist yanıtı sorunsallaştırmaktadır.

Yeni görevinin Josie'nin kalbinin derinliklerini öğrenmek olarak açıklayan Klara, bunu çok odalı bir evin odalarını öğrenmek metaforuyla anlamlandırmaya çalışır. Bu son derece düz, basit ve bir o kadar da kolay gözüken teknik yaklaşıma Mr. Paul insanın karmaşık doğası örneğiyle karşıık verir: "O odanın da içinde yine bir oda daha. Odaların içinde odalar, onların içinde tekrar odalar" (Ishiguro, 2021: 189). Insan ruhu ve duygu dünyası çok yapılı ve karmaşık doğasıyla bir matruşka bebeği andırmaktadır. Klara için bu sorunun da bir çözümü mevcuttur. Her şeyin olduğu gibi odaların da mutlaka bir sınırı vardır ve bir yerde bitmek zorundadır.

Insan doğasının teknolojikleştirilmesi ve insanın başka insanları tasarlayarak üretmenin ahlaki boyutu Mr. Paul'ün kaygılarıyla vurgulanmaktadır. Bu kaygının zeminini "değer ölçütlerimizi temellendiren sınırın kayması" oluşturmaktadır (Habermas, 2019: 56). Insan doğasına müdahale etme, çeşitli saiklerle tasarlama, geleceği ile ilgili karar alma ve insana dair her şeyin taklit edilebilir olacağını varsayma son derece önemli ahlaki sorgulamaları da beraberinde getirmektedir.

Ishiguro'nun bu noktada yüksek robot teknolojisi ile kuşatılmış bir yakın gelecekte yaşanacaklara dair fütürist veya gerçekçi saptamalar yapan bir yazar olmaktan ziyade "ahlakçı" (moralist) bir tavrı öne çıkarmaya çalıştığı görülmektedir. Klara'nın Josie'nin yerine geçme planının okuyucuya tutmaya çalıştığı aynada insanlığın teknolojik gelişmeleri nasıl yöneteceği, verili doğa ile üretilen yapay doğa arasındaki çatışmaları ve olası sonuçlarını nasıl yorumlayacağı yansıtılmaktadır.

Ishiguro'nun insan yaşamına ve insanın biricikliğine dair soruşturma yaparken diyalektik bir materyalizmi olumsuzlayan ve yerine metafizik ve tinselci bir yaklaşıma başvurduğu gözlemlenmektedir. Josie'nin babası Mr. Paul'un insan kalbi mecazıyla dile getirdiği her insanı eşsiz kılan özün ve insanın yerinin doldurulamayacağına dair imasının bir benzerini Klara'nın 
Josie için kendi kendine düşündüğü kurtarma planında da görmek mümkündür.

Güneş enerjisiyle çalışan Klara için Güneş, insanlara ifade ettiğinden çok daha fazlası demektir. Romanın adında da Klara ile birlikte kendine yer bulan Güneş, Klara'nın bir tür dinsel bağlılık geliştirdiği aşkın bir güç olarak sunulmaktadır. Josie'nin mutlu olması onun iyileşmesini gerektirdiği için Klara Güneş’ten yardım istemeyi planlar: “Josie'nin Güneş’in özel yardımını alması için, Güneş'in dikkatini belirli ve fark edilir bir şekilde Josie'nin durumuna çekmek gerekebilirdi” (Ishiguro, 2021: 103). Bu konuda Rick'ten destek alarak evlerinin yakınlarında bulunan ve Güneş'in batışının denk geldiği Mr. McBain'in ambarına gider. Klara için bu ambar Güneş'in dinlenme yeridir veya bir başka deyişle bir çeşit tapınaktır. Rick'i geride bırakarak tek başına girdiği ambarda Klara Güneş'e yalvarmaya başlar: “Lütfen Josie’yi iyileştir. Tıpkı dilenci adamı iyileştirdiğin gibi” (Ishiguro, 2021: 143).

Dua ve yakarışı insansı bir robotun ağzından işitmek her ne kadar ironik ve çarpıcı gözükse de Klara'nın dindar bağlılı̆̆ı sınırlı ve yüzeysel değildir. Klara bütün adanmışlığıyla Güneş'e yakarmanın ötesinde yapacağı iyiliğin karşıı̆̆ında ona bir armağan sunmak ister. Bu armağanın Güneş’i ve dünya yaşamını tehdit eden hava kirliliği ile ilgili olması şaşırtıcı olmayacaktır. Yakın gelecekteki olası çevre sorunlarına da dikkat çekilen bu teklifte Klara'nın içtenliği ve kararlılığı görülür: "Güneş’in Hava Kirliliği'nden hoşlanmadığını biliyorum. Sizi ne kadar üzdüğünü ve kızdırdığını. Eh, bunu yaratan makineyi gördüm ve tanıdım. Farz edelim bir şekilde ben bu makineyi bulabildim ve yok edebildim. Hava Kirliliği yaratmasına son vermek için. O zaman, bunun karşıı̆ında, Josie’ye özel yardımınızdan vermeyi düşünür müsünüz?” (Ishiguro, 2021: 144).

Klara'nın hava kirliliğine yol açtığı ve "Cootings Makinesi” adını verdiği çevre kirleten oluşumları bulup yok etme planları somutlaşmaya başlar. Ancak bunun için desteğe intiyacı olacaktır ve bunu manidar bir şekilde her insanı özel kılan bir duygu dünyası ve kalpten bahseden Josie'nin babası Mr. Paul'den görecektir. "Üç bacasından Hava Kirliliği fışkırtan şey”i bulduklarında Mr Paul'ün mühendisliğinin de yardımıyla bir plan yaparlar. Bu noktada Klara'nın Josie'nin iyileşmesi için ortaya koyduğu fedakârlık örneği dikkat çekicidir. Makineyi devre dışı bırakacak P-E-G Dokuz solüsyonu Klara'nın başının içinde de bulunmaktadır. Kendisinden alınacak solüsyonla makinenin durdurulabileceğine emin olan Klara tereddüt etmeden bir miktar alınmasına razı olur. Bilişsel yeteneklerinin zayıflaması intimalini göze alan Kla- 
ra'nın kulağının altından bir delikle bir miktar sıvı alınır ve makine devre dışı bırakılır.

Klara'nın umutlu bekleyişi Josie'nin durumunun kötüleşmesiyle sekteye uğrar. Duasının kabul edilmemesinin gerekçesini düşünürken bir gün hava kirliliğine yol açan bu sefer daha büyük bir makine görür. Mr. McBain'in ambarına, diğer bir deyişle, Güneş'in tapınağına bir ziyarette daha bulunur. Görevini tam anlamılla yerine getiremediği için özür dileyip Josie için bir kez daha merhamet talep eder: "En derin arzum Güneş'in büyük iyilikseverliğini bir kez daha göstermesi” (Ishiguro, 2021: 235).

Klara'nın yakarışları ile yön ve konum duygusunu belli oranda kaybetme pahasına yaptığı özverili davranış sonunda meyvesini verir ve Josie mucizevi bir şekilde iyileşir. Romanın son bölümünde Josie'nin çocukluktan yetişkinliğe geçmesinden bahsedilir. Artık sağlıklı ve üniversiteye gitmeye hazırlanan bir genç kız vardır. Zamanında Klara'nın ne yaptığına anlam veremeyip "batıl inançlı" diye önemsemedikleri eylemlerine aile üyeleri en azından bugün müteşekkir gözükmektedirler.

\section{Sonuç}

Klara ile Güneş'in bir tür öncüsü ve yoldaşı sayılabilecek Beni Asla Bırakma adlı romanda Ishiguro başkalarına organlarını bağışlamak için yetiştirilen kopya insanların hikâyesini anlatır. Birbirine âşık olan iki genç sevgilerini ispat etmek için yaptıkları sanat çalışmalarını gösterip bağış yapmaktan muaf olmayı talep ettiklerinde olumsuz bir cevap alırlar ama bu çalışmaların amacı şu şekilde açıklanır: "sizin ruhlarınız olduğunu kanıtlamak için yaptık bunu" (2008: 246). Her ne kadar klonlanmış insan bile olsa Ishiguro'nun "insanı insan yapan nedir, insanın bir özü var mıdır" sorularına metafizik ve tinselci (spiritualist) yaklaşımı Klara ile Güneş'te daha belirgin bir biçimde devam etmektedir.

Yazarın her iki romanda da hissettirdiği moralist tavır Klara ile Güneş’te çok daha iyimser ve insan doğasını kutlayıcı bir biçim kazanır. Materyalist bakış açısının olumsuzlandığı ve tinselci yaklaşım karşısında yenilgiye uğradığı bir anlatı ön plana çıkar. Mr. Capaldi'nin temsil ettiği maddeci ve mekanik anlayış romanın başlığında Klara ile yer bulan Güneş ve sembolleştirdiği tinselci yaklaşım karşısında kaybeder. Insanın tamamen kopyalanabilir olup olmadığına dair sorunsallaştırmaya roman boyunca yazarın aradığı yanıt Josie'nin babası Mr. Paul'ün kaygılarında ve kullandığı kalbin derinlikleri metaforunda gizlidir. Sevgi, şefkat, özveri, umut ve kısacası insanın sınırsız 
duygu evreni hiçbir mekanik düzenlemenin yerini alamayacağı, değiş tokuş edemeyeceği bir öz barındırmaktadır.

Ishiguro, insan doğasına dikkat çekip her cephesiyle dijitalleşen bir çağda insanı yeniden tanımlamaya çalışırken yüksek robotik teknolojiye ve onlarla kurulan etkileşime farklı bir yorum getirmiştir. Genetik artırmaların, "yükseltilmiş" insan gruplarının çoğaldığı, öjenik çağrışımları olan uygulamaların boy gösterdiği, yabancılaşma, yalnızlaşma ve "şeyleşme"nin arttığı, verili ile yapay olan arasındaki sınıın bulanıklaştığı bir çağda "teknolojik gelişmenin özyıkım olasılığını güçlendirmesi”ne karşı bir can simidi olarak tekrar dönüp insan doğasına bakmayı, maddi ve mekanik olanın ötesinde bir öze ulaşmayı salık vermektedir (Lents, 2020: 207).

\section{Kaynakça}

Asimov, Isaac (2016). Ben, Robot. Çev. Ekin Odabaş. İstanbul: İthaki Yayınları.

Bewes, Timothy (2008). Şeyleşme. Çev. Deniz Soysal. İstanbul: Metis Yayınları.

Borenstein, Jason \& Pearson, Yvette (2012). "Robot Caregivers: Ethical Issues across the Human Lifespan". Robot Ethics: The Ethical and Social Implications of Robotics. Ed. Patrick Lin et. al. Cambridge: MIT Press, 251-265.

Habermas, Jürgen (2019). Insan Doğasının Geleceği. Çev. Kaan H. Ökten. istanbul: Alfa Yayınları.

Ishiguro, Kazuo (2008). Beni Asla Bırakma. Çev. Mine Haydaroğlu. İstanbul: Yapı Kredi Yayınları.

Ishiguro, Kazuo (2021). Klara ile Güneş. Çev. Lale Akalın. İstanbul: Yapı Kredi Yayınları.

Lents, Nathan H. (2020). Insanın Kusurları. Çev. Şiirsel Taş. İstanbul: Metis Yayınları.

Meacham, Darian \& Studley, Matthew (2017). "Could a Robot Care? It's All in the Movement". Robot Ethics 2.0: From Autonomous Cars to Artificial Intelligence. Ed. Patrick Lin et al. New York: Oxford, 97-112.

Moor, James H. (2011). "The Nature, Importance and Difficulty of Machine Ethics". Machine Ethics. Eds. Michael Anderson \& Susan Leigh Anderson. New York: Cambridge, 13-20. 
Shaw-Garlock, Glenda (2009). "Looking Forward to Sociable Robots". International Journal of Social Robotics, 1(3): 249-260.

Tura, Saffet Murat (2011). Madde ve Mana. İstanbul: Metis Yayınları.

URL-1: "Kazuo Ishiguro on How His New Novel Klara and the Sun Is a Celebration of Humanity". https://time.com/5943376/kazuo-ishigurointerview/ (Erişim: 09.06.2021).

Wallach, Wendell \& Allen, Colin (2009). Moral Machines. New York: Oxford.

"COPE-Dergi Editörleri İçin Davranış Kuralları ve En İyi Uygulama ilkeleri” çerçevesinde aşağıdaki beyanlara yer verilmiştir:

Etik Kurul Belgesi: Bu çalışma için etik kurul belgesi gerekmemektedir.

Çıkar Çatışması Beyanı: Bu makalenin araştırması, yazarlığı veya yayınlanmasıyla ilgili olarak yazarın potansiyel bir çıkar çatışması yoktur.

The following statements are made in the framework of "COPE-Code of Conduct and Best Practices Guidelines for Journal Editors":

Ethics Committee Approval: Ethics committee approval is not required for this study.

Declaration of Conflicting Interests: The author has no potential conflict of interest regarding research, authorship or publication of this article. 